\title{
Correction: Discovery and characterization of UipA, a uranium- and iron-binding PepSY protein involved in uranium tolerance by soil bacteria
}

Nicolas Gallois (D), Béatrice Alpha-Bazin, Nicolas Bremond, Philippe Ortet (iD, Mohamed Barakat, Laurie Piette, Abbas Mohamad Ali, David Lemaire, Pierre Legrand (iD), Nicolas Theodorakopoulos, Magali Floriani (D), Laureline Février (D), Christophe Den Auwer (iD), Pascal Arnoux, Catherine Berthomieu, Jean Armengaud (iD) and Virginie Chapon (iD

(c) The Author(s), under exclusive licence to International Society for Microbial Ecology 2021

The ISME Journal (2022) 16:902-903; https://doi.org/10.1038/s41396-021-01164-w

Correction to: The ISME Journal https://doi.org/10.1038/s41396021-01113-7, published online 23 September 2021.

Following the publication of this article, the authors noted a mixup in the table captions.
The tables should have appeared as shown below: (Tables 1 and 2). The original article has been corrected.

\begin{tabular}{|c|c|c|c|c|c|c|c|c|c|c|c|}
\hline \multicolumn{2}{|c|}{ ViU2A } & \multicolumn{3}{|l|}{ HG3 } & \multicolumn{3}{|l|}{ A9 } & \multicolumn{4}{|c|}{ ViU22 } \\
\hline $4 \mathrm{~h}$ & $24 \mathrm{~h}$ & $0.5 \mathrm{~h}$ & $4 \mathrm{~h}$ & $24 \mathrm{~h}$ & $0.5 \mathrm{~h}$ & $4 \mathrm{~h}$ & $24 \mathrm{~h}$ & $0.5 \mathrm{~h}$ & $4 \mathrm{~h}$ & $24 \mathrm{~h}$ & Functional annotation and subcellular localization \\
\hline 2 & ns & ns & 6.8 & 12 & 2.2 & 1.7 & 4.8 & ns & ns & ns & Unknown function (UipB)_-membrane \\
\hline nd & nd & ns & ns & 2 & ns & 3.2 & 9.9 & nd & nd & nd & $\begin{array}{l}\text { ABC transporter ATP-binding protein } \mathrm{YxdL}- \\
\text { membrane }\end{array}$ \\
\hline ns & 1.8 & 1.3 & 5.4 & 3 & abs & abs & abs & abs & abs & abs & $\begin{array}{l}\text { 4-hydroxyacetophenone monooxygenase- } \\
\text { membrane }\end{array}$ \\
\hline 1.7 & 4.7 & ns & 2.0 & 3.1 & ns & 1.5 & 5.3 & ns & -1.3 & ns & Periplasmic serine endoprotease DegP — membrane \\
\hline nd & nd & ns & ns & ns & ns & 2.8 & 5.2 & nd & nd & nd & Unknown function \\
\hline ns & ns & ns & 4.7 & -1.4 & 2 & ns & ns & nd & nd & nd & Unknown function \\
\hline
\end{tabular}

The data are sorted in descending order of maximum FC value. FC (below 1.5) or $p$ value (above 0.05 ): not significant (ns); not detected in the proteome (nd); absent gene (abs). Proteins specific to the uranium-tolerant strains are shown in italics. 
Table 2. Macroscopic dissociation constants for 1:1 and 1:2 protein-metal complexes of UipA $A_{\text {ext }}$ proteins and selected metals.

\begin{tabular}{lllllll} 
Metal & UipA $_{\text {ext }}-$ ViU2A & & UipA $_{\text {ext }}$-HG3 & & UipA \\
& Prot-Me & Prot-Me2 & Prot-Me & Prot-Me2 & Prot-Me \\
Uranyl $\left(\mathrm{UO}_{2}{ }^{2+}\right)$ & $(4.2 \pm 1.8) \times 10^{-8}$ & $(5.0 \pm 1.1) \times 10^{-8}$ & $(3.1 \pm 2.5) \times 10^{-8}$ & $(3.7 \pm 1.5) \times 10^{-8}$ & $(1.3 \pm 0.6) \times 10^{-9}$ & $(3.6 \pm 0.2) \times 10^{-8}$ \\
\hline Iron $\left(\mathrm{Fe}^{3+}\right)$ & $(3.3 \pm 1.1) \times 10^{-9}$ & $(2.3 \pm 0.1) \times 10^{-8}$ & $(2.9 \pm 0.2) \times 10^{-8}$ & $(2.6 \pm 0.4) \times 10^{-5}$ & $(3.2 \pm 0.3) \times 10^{-8}$ & $(4.4 \pm 0.1) \times 10^{-5}$ \\
Calcium $\left(\mathrm{Ca}^{2+}\right)$ & $(1.1 \pm 0.7) \times 10^{-4}$ & $(6.9 \pm 0.7) \times 10^{-4}$ & $(1.2 \pm 0.5) \times 10^{-4}$ & $(2.5 \pm 0.2) \times 10^{-3}$ & $(2.9 \pm 1.6) \times 10^{-4}$ & - \\
Nickel $\left(\mathrm{Ni}^{2+}\right)$ & $(1.7 \pm 0.3) \times 10^{-5}$ & $(2.2 \pm 0.1) \times 10^{-5}$ & $(4.0 \pm 0.9) \times 10^{-5}$ & $(2.8 \pm 0.2) \times 10^{-5}$ & $(1.8 \pm 0.8) \times 10^{-4}$ & - \\
\hline Zinc $\left(\mathrm{Zn}^{2+}\right)$ & $(8.9 \pm 3.2) \times 10^{-5}$ & $(1.3 \pm 0.1) \times 10^{-4}$ & $(3.3 \pm 0.9) \times 10^{-4}$ & $(6.9 \pm 0.4) \times 10^{-5}$ & $(5.5 \pm 4.4) \times 10^{-5}$ & -
\end{tabular}

Values are given in $\mathrm{M} \pm$ corresponds to the standard deviation, calculated from three independent experiments. 